\title{
Signature program: a platform of basket trials
}

Research Paper

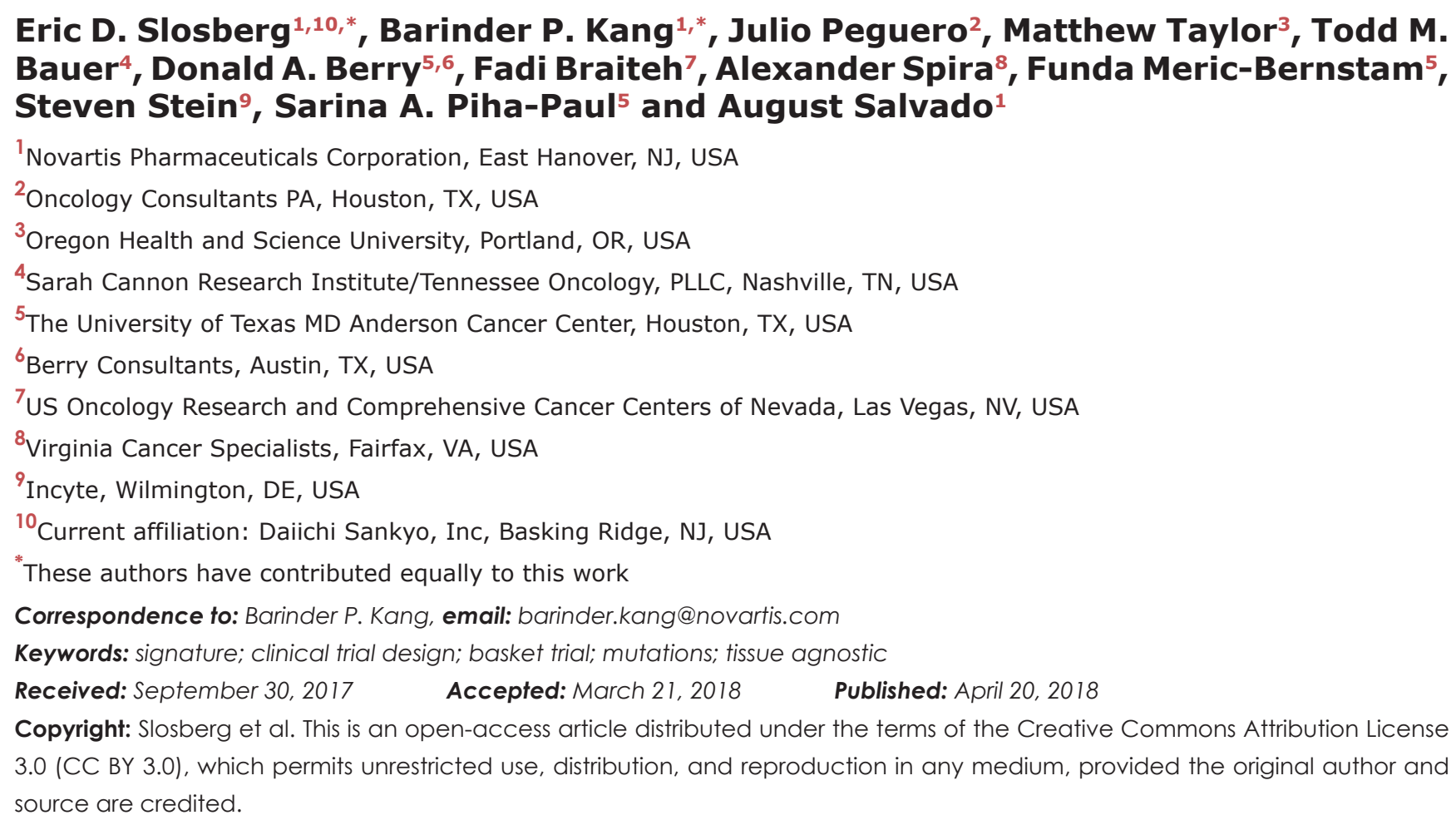

\section{ABSTRACT}

Investigating targeted therapies can be challenging due to diverse tumor mutations and slow patient accrual for clinical studies. The Signature Program is a series of 8 phase 2, agent-specific basket protocols using a rapid study start-up approach involving no predetermined study sites. Each protocol evaluated 1 agent (buparlisib, dovitinib, binimetinib, encorafenib, sonidegib, BGJ398, ceritinib, or ribociclib) in patients with solid or hematologic malignancies and an actionable mutation. The primary endpoint of each study was the clinical benefit rate (ie, complete or partial response, or stable disease) at 16 weeks. A total of 192 individual sites were opened in the United States, with a median start-up time of 3.6 weeks. The most common tumor types among the 595 treated patients were colorectal $(9.2 \%)$, non-small cell lung adenocarcinoma $(9.1 \%)$, and ovarian $(8.4 \%)$. Frequent genetic alterations were in PIK3CA, RAS, p16, and PTEN. Overall, 30 partial or complete responses were observed with 6 compounds in 16 tumor types. The Signature Program presents a unique and successful approach for rapid signal finding across multiple tumors and allowed various agents to be evaluated in patients with rare alterations. Incorporating these program features in conventional studies could lead to improved trial efficiencies and patient outcomes.

\section{INTRODUCTION}

Genetic profiling has become readily accessible to oncologists in most practice settings in the United States. This technology can identify potentially actionable genetic alterations in a tumor, allowing physicians to match individual patients with a targeted therapy [1,2]. Although agents targeting a wide range of molecules and pathways have been discovered, investigating these therapies can be challenging due to the diversity of molecular drivers, 
even within tumors of the same histology, and the rarity of these patients at any one hospital or clinic. This results in operational inefficiencies, slow patient accrual, and long timelines for clinical trials [2-4]. One approach to match patients with genetic alterations to targeted therapies is the basket trial. Basket trials use a hypothesis-generating approach in which enrollment and treatment assignment are molecularly driven [3], and a single targeted agent is tested simultaneously in tumors of different histologies that have genetic alterations in the targeted pathway [5].

Novartis Pharmaceuticals Corporation built on this approach and launched the Signature Program, a series of 8 agent-specific, open-label, phase 2 basket trials in which research-qualified academic or community physicians in the United States could participate (Table 1). Each trial investigated a single agent, and enrollment was based on tissue-agnostic, molecularly driven criteria. The statistical design was similar for each protocol and used a patientsparing approach and a Bayesian adaptive design [6]. Importantly, participating sites were not predetermined but were rapidly opened after a potentially eligible patient was identified (Figure 1).

The Signature Program had 4 key objectives: (1) rapidly match each patient with a treatment that targets the tumor's molecular abnormality, (2) discover the clinical potential of pipeline compounds by matching the drug's mechanism of action to molecular targets across a range of malignancies, (3) develop a better understanding of the underlying disease biology of the individual patient, and
(4) develop a platform that can accelerate downstream clinical development by rapidly focusing new targeted agents on indications with the clearest signals for further tissue-specific trials. Herein, we present an overview of this novel clinical trial approach and report the overall findings from the program. Analyses of each individual protocol will be reported in subsequent publications.

\section{RESULTS}

As of the data cutoff (December 18, 2017 [October 1, 2015, for binimetinib]), 1674 prescreening checklists were received, 1568 patients had actionable mutations, and 988 patients provided informed consent. Overall, 595 patients received treatment. The main reasons for patient drop-off were unacceptable laboratory value(s) (116/414), unacceptable test procedure result(s) (57/414), and other (99/414), which included screening failure, initiation of an alternative therapy, expired consent, ineligible mutational status, and death. Patients were enrolled at 192 individual sites (396 protocol openings) including research networks, community sites, and academic institutions (Table 2). Each arm was considered a separate protocol, resulting in site overlap and the possibility for individual sites to be counted twice. The median start-up time was 3.6 weeks (range, 0.335.9 weeks) across all sites (mean, 5.9 weeks) and was shortest for research networks (2.6 weeks) and longest for academic institutions (8.1 weeks).

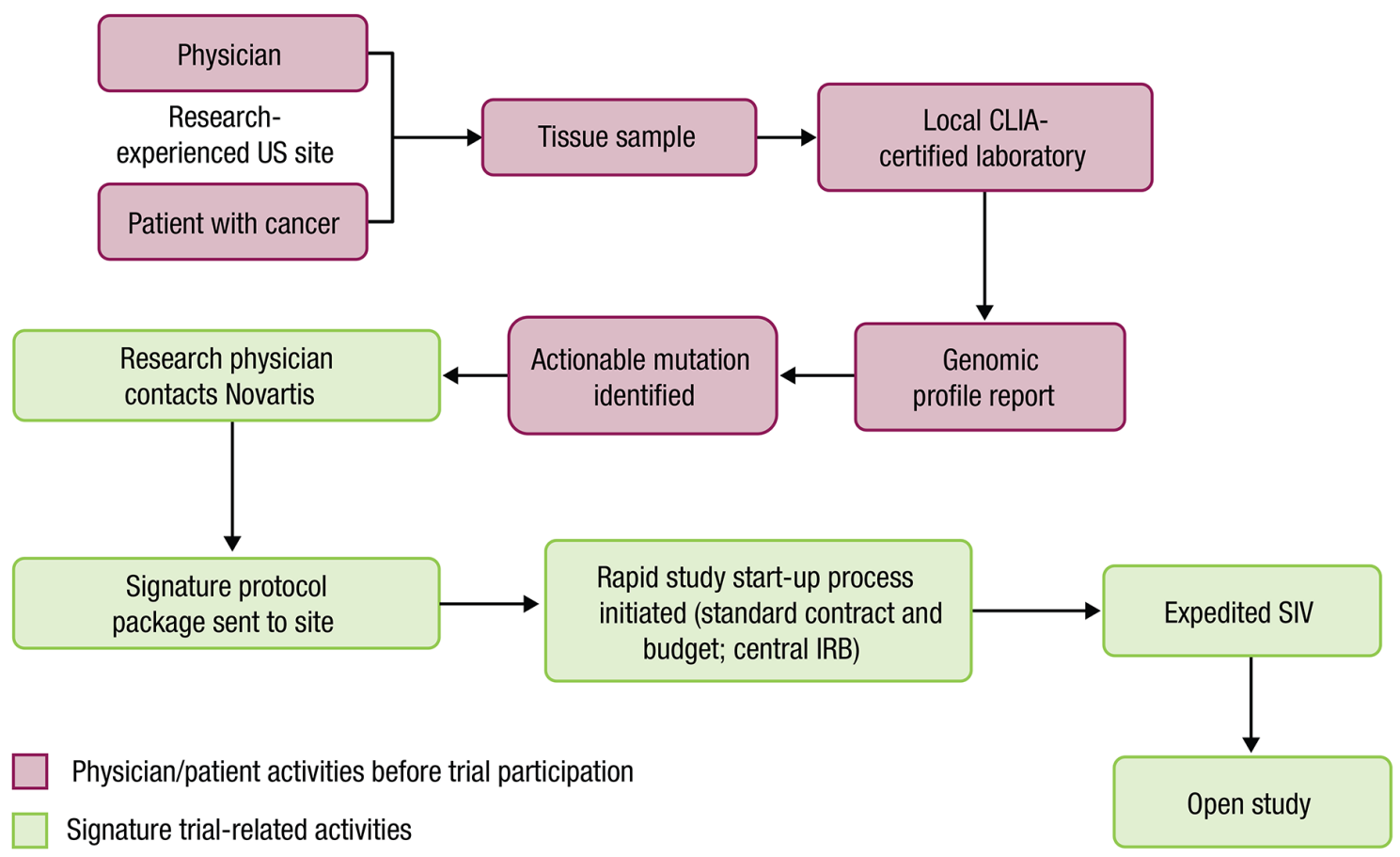

Figure 1: Signature Program protocol start-up process. Each protocol excluded patients with certain tumor types, including those for which the agent being studied has shown no benefit and those for which key studies are planned or ongoing. CLIA, Clinical Laboratory Improvement Amendments; IRB, institutional review board; SIV, site initiation visit. 
Table 1: Agents included in the Signature Program

\begin{tabular}{|c|c|c|c|c|}
\hline Agent & Target & Mutations Required & Tumor Types Excluded & ClinicalTrials.gov ID \\
\hline Buparlisib (BKM120) [28] & Pan-P13K & $\begin{array}{l}\text { PIK3CA mutation/ } \\
\text { amplification, } P T E N \\
\text { mutation/loss, or } \\
\text { PIK3R1 mutation }\end{array}$ & $\begin{array}{l}\text { Endometrial, glioblastoma, } \\
\text { NSCLC, prostate, breast }\end{array}$ & NCT01833169 \\
\hline Dovitinib (TKI258) [29] & Various RTKs & $\begin{array}{l}\text { FGFR1-3, FLT3, } \\
\text { or } c \text {-KIT mutation/ } \\
\text { amplification } \\
\text { or } P D G F R \alpha / \beta, \\
V E G F R 1-2, R E T, \operatorname{Trk} A \\
(N T R K 1), \text { or } C S F-1 R \\
\text { mutation }\end{array}$ & $\begin{array}{l}\text { Multiple myeloma, } \\
\text { urothelial, AML (FLT3+), } \\
\text { hepatocellular, endometrial, } \\
\text { renal cell, breast } \\
\text { (metastatic), squamous } \\
\text { NSCLC }\end{array}$ & NCT01831726 \\
\hline Binimetinib (MEK 162) ${ }^{\mathrm{a}}[30]$ & $\begin{array}{l}\text { MEK (RAS } \\
\text { pathway) }\end{array}$ & $\begin{array}{l}R A S, R A F, \\
M E K 1 / M E K 2, \text { or } N F 1\end{array}$ & $\begin{array}{l}\text { Pancreatic, biliary, } \\
\text { colorectal, ovarian (low- } \\
\text { grade serous), melanoma }\end{array}$ & NCT01885195 \\
\hline Encorafenib (LGX818) ${ }^{\mathrm{a}}[31]$ & BRAF & $B R A F \mathrm{~V} 600 \mathrm{E}$ & $\begin{array}{l}\text { Melanoma, colorectal, } \\
\text { primary CNS }\end{array}$ & NCT01981187 \\
\hline Sonidegib (LDE225) ${ }^{\mathrm{b}}$ [32] & $\begin{array}{l}\text { SMO } \\
\text { (hedgehog } \\
\text { pathway) }\end{array}$ & PTCH1 or $S M O$ & $\begin{array}{l}\text { Basal cell, pancreatic, } \\
\text { medulloblastoma/primary } \\
\text { CNS, CML, ALL, AML }\end{array}$ & NCT02002689 \\
\hline BGJ398 [33] & FGFR & $\begin{array}{l}F G F R \text { mutation/ } \\
\text { amplification/fusion, } \\
F G F R 1-4 \text { translocation, } \\
\text { or ligand amplification }\end{array}$ & $\begin{array}{l}\text { Urothelial, } \\
\text { cholangiocarcinoma, } \\
\text { glioblastoma multiforme }\end{array}$ & NCT02160041 \\
\hline Ceritinib $\left(\right.$ LDK378) ${ }^{\mathrm{c}}[34]$ & ALK/ROS1 & $\begin{array}{l}\text { ALK/ROS1 mutation/ } \\
\text { amplification/ } \\
\text { translocation/ } \\
\text { rearrangement }\end{array}$ & $\mathrm{ALK}+\mathrm{NSCLC}$ & NCT02186821 \\
\hline Ribociclib (LEE011)d [35] & CDK4/6 & $\begin{array}{l}C D K 4 / 6 \text { mutation/ } \\
\text { amplification, cyclin } \\
D 1 / D 3 \text { amplification, } \\
\text { or } p 16 \text { mutation/loss }\end{array}$ & $\begin{array}{l}\text { ER+ breast, mantle cell } \\
\text { lymphoma, teratoma, } \\
\text { liposarcoma, castration- } \\
\text { resistant prostate, melanoma }\end{array}$ & NCT02187783 \\
\hline
\end{tabular}

Abbreviations: ALK, anaplastic lymphoma kinase; ALL, acute lymphocytic leukemia; AML, acute myeloid leukemia; CDK, cyclindependent kinase; CML, chronic myeloid leukemia; CNS, central nervous system; CSF-1R, colony-stimulating factor 1 receptor; ER, estrogen receptor; FGFR, fibroblast growth factor receptor; FLT3, fms-related tyrosine kinase 3; MEK, mitogen-activated protein kinase/extracellular signal-regulated kinase kinase; NF1, neurofibromatosis type 1; NSCLC, non-small cell lung cancer; NTRK1, neurotrophic tyrosine kinase receptor type 1; PDGFR, platelet-derived growth factor receptor; PI3K, phosphatidylinositol 3-kinase; PIK3CA, phosphatidylinositol 4,5-bisphosphate 3-kinase catalytic subunit $\alpha$; PIK3R1, phosphatidylinositol 3-kinase regulatory subunit polypeptide 1; PTCH1, patched 1; PTEN, phosphatase and tensin homolog; RTK, receptor tyrosine kinase; SMO, smoothened; TrkA, tropomyosin receptor kinase A; VEGFR, vascular endothelial growth factor receptor.

aBinimetinib (MEK162) and encorafenib (LGX818) are owned by Array BioPharma.

bSonidegib (LDE225; Odomzo), owned by Sun Pharmaceuticals, is a hedgehog pathway inhibitor indicated for the treatment of adult patients with locally advanced basal cell carcinoma that has recurred following surgery or radiation therapy or those who are not candidates for surgery or radiation therapy [36].

${ }^{\mathrm{c}}$ Ceritinib (LDK378) is approved by the US Food and Drug Administration for the second-line treatment of ALK+ NSCLC [37]. ${ }^{d}$ Ribociclib (LEE011; Kisqali) was discovered by the Novartis Institutes for Biomedical Research in collaboration with Astex Pharmaceuticals. Kisqali is a kinase inhibitor indicated in combination with an aromatase inhibitor as initial endocrine-based therapy for the treatment of postmenopausal women with hormone receptor-positive, human epidermal growth factor receptor 2-negative advanced or metastatic breast cancer [38]. 
Table 2: Signature Program enrollment

\begin{tabular}{lccccc}
\hline Site type & Sites, $\mathbf{n}(\%)^{\mathbf{a}}$ & \multicolumn{2}{c}{ Time to trial start, weeks } & \multicolumn{2}{c}{ Patients treated, $\mathbf{n}$} \\
\cline { 3 - 5 } & & Mean & Median & Range & 166 \\
\hline Research network & $118(30)$ & 3.6 & 2.6 & $0.3-34.8$ & 196 \\
Community site & $197(50)$ & 5.4 & 3.6 & $1.0-35.9$ & 233 \\
Academic & $81(20)$ & 10.7 & 8.1 & $1.4-33.7$ & 595 \\
Total & 396 & 5.94 & 3.6 & $0.3-35.9$ & \\
\hline
\end{tabular}

aPercentage among total protocol openings $(\mathrm{N}=396)$ at 192 individual sites (a single site may have opened $>1$ protocol).

Across all protocols, the median patient age was 61 years, and the median number of prior lines of drug therapy was 3 (range, 0-19) (Table 3). The most commonly enrolled tumor types were colorectal $(n=55[9.2 \%])$, non-small cell lung cancer (NSCLC) adenocarcinoma $(\mathrm{n}=54$ [9.1\%]), ovarian $(n=50[8.4 \%])$, sarcoma $(n=45[7.6 \%])$, head and neck squamous cell carcinoma $(n=32[5.4 \%])$, and uterine $(n=20[3.4 \%])$. Patients with a variety of rarer tumor types (eg, gallbladder/biliary [n=17 (2.9\%)], anal $[\mathrm{n}=10(1.7 \%)]$, mesothelioma $[\mathrm{n}=6(1.0 \%)]$, vaginal $[\mathrm{n}=$ $5(0.8 \%)]$, germ cell $[n=3(0.5 \%)]$, thymus $[n=4(0.7 \%)]$, and penile $[\mathrm{n}=2(0.3 \%)])$ also were enrolled. By the data cutoff, tumor-type cohorts were formed for all agents except sonidegib, as only 10 patients were accrued over a period of 11 months (Table 4). In an average of 9.1 months, 13 cohorts reached the futility analysis target accrual of $\geq 10$ patients at 16 weeks. Timing was based on the date of the first dose received by the first and last patients in a cohort. Overall, 4 of these cohorts closed due to futility (Table 4).

A wide array of genetic alterations were represented (Figure 2). The most frequent alterations (in $\geq 10 \%$ of patients) were phosphatidylinositol 4,5-bisphosphate 3-kinase catalytic subunit $\alpha(P I K 3 C A ; \mathrm{n}=93[15.6 \%]$; gene mutation, $\mathrm{n}=74$; gene amplification, $\mathrm{n}=19), R A S$ $(\mathrm{n}=80[13.4 \%]$; Kirsten rat sarcoma viral oncogene homolog [KRAS], $\mathrm{n}=67$; neuroblastoma $\mathrm{RAS}$ viral oncogene homolog $[N R A S], \mathrm{n}=14$; Harvey rat sarcoma viral oncogene homolog [HRAS], $\mathrm{n}=3$; patients may have been counted in more than 1 RAS category), cyclin-dependent kinase inhibitor 2A encoding p16 (CDKN2A; $\mathrm{n}=78[13.1 \%])$, and phosphatase and tensin homolog (PTEN; $\mathrm{n}=60$ [10.1\%]; mutation/loss, $\mathrm{n}=37$; loss by immunohistochemistry, $\mathrm{n}=23$ ). The primary endpoint-clinical benefit rate (ie, partial response, complete response, or stable disease) at 16 weeks - was 17\% (101/593; Table 5). Overall, 30 partial or complete responses (20 confirmed) were observed with 6 of 8 compounds in 16 of 29 tumor types considered (Table 6).

As an example, one responder, an 87-year-old woman with poorly differentiated colon adenocarcinoma and peritoneal carcinomatosis with anaplastic lymphoma kinase $(A L K)$-striatin calmodulin-binding protein $(S T R N)$ fusion (as well as genetic alterations in $K R A S$, serine/ threonine kinase 11 [STK11], and TP53), was treated with ceritinib [7]. This patient was previously treated with 16 cycles of FOLFOX (leucovorin, 5-fluorouracil [5-FU], oxaliplatin), 8 cycles of FOLFIRI (leucovorin, 5-FU, irinotecan), and 6 cycles of 5-FU, and had progressive disease. At the data cutoff, the patient remained on ceritinib after $>31$ weeks of treatment. Peritoneal masses were stable in size, and a mass protruding through the skin from the periumbilical node had regressed. Another patient experienced an unexpected complete response to the mitogen-activated protein kinase/extracellular signalregulated kinase kinase $(M E K)$ inhibitor binimetinib. This 70-year-old man had acute myeloid leukemia with NRAS mutations (G12D, Q61R, E62K), and had received 1 prior line of therapy.

\section{DISCUSSION}

The Signature Program is an industry-sponsored series of compound-specific protocols designed to operationalize an approach for rapid signal finding that could potentially improve patient outcomes and increase efficiencies for further development of the compounds involved. The program spanned the spectrum of researchqualified practices - from research-oriented community practices to academic investigators - with the program design allowing for a rapid study start-up at each treatment site. For instance, the mean start-up time was 5.9 weeks (median, 3.6 weeks) compared with 10.4 months for traditional phase 2 to 4 oncology trials [8]. Although not a direct comparison, this short start-up time allowed patients to be treated promptly and the efficacy of the drug to be assessed quickly.

Patients were matched with a targeted agent that was predicted to result in clinical benefit regardless of tumor type. Responses were seen in some patients despite these patients having exhausted standard therapy options $(\geq 3$ in some patients) or having no other available treatment options. Overall, the program provided treatment options to a patient population with advanced disease and few to no available treatment options. Although the response rate was not high, our findings are consistent with those of the recently published MOSCATO-01 trial and preliminary data from the ongoing ProfilER study, which used highthroughput genomics to select therapies for difficult-to- 
Table 3: Demographics of enrolled patients

\begin{tabular}{lccccccccc}
\hline & $\begin{array}{c}\text { Buparlisib } \\
\text { (BKM120) }\end{array}$ & $\begin{array}{c}\text { Dovitinib } \\
\text { (TKI258) }\end{array}$ & $\begin{array}{c}\text { Binimetinib } \\
\text { (MEK162) }\end{array}$ & $\begin{array}{c}\text { Encorafenib } \\
\text { (LGX818) }\end{array}$ & $\begin{array}{c}\text { Sonidegib } \\
\text { (LDE225) }\end{array}$ & BGJ398 & $\begin{array}{c}\text { Ceritinib } \\
\text { (LDK378) }\end{array}$ & $\begin{array}{c}\text { Ribociclib } \\
\text { (LEE011) }\end{array}$ & $\begin{array}{c}\text { Total } \\
\text { Patients treated, } \\
\mathrm{n}\end{array}$ \\
\hline
\end{tabular}

Abbreviations: ECOG, Eastern Cooperative Oncology Group; PS, performance status.

${ }^{a}$ May not equal $100 \%$ due to rounding.

${ }^{\mathrm{b}}$ Includes 1 patient with ECOG PS of 2 at baseline.

${ }^{\mathrm{c}}$ Only prior drug therapies are included.

Table 4: Tumor cohorts $(n \geq 4$ patients)

\begin{tabular}{|c|c|c|c|c|c|c|c|}
\hline Agent $^{\mathrm{a}}$ & $\begin{array}{l}\text { Buparlisib } \\
\text { (BKM120) }\end{array}$ & $\begin{array}{l}\text { Dovitinib } \\
\text { (TKI258) }\end{array}$ & $\begin{array}{l}\text { Binimetinib } \\
\text { (MEK162) }\end{array}$ & $\begin{array}{c}\text { Encorafenib } \\
\text { (LGX818) }\end{array}$ & BGJ398 & $\begin{array}{l}\text { Ceritinib } \\
\text { (LDK378) }\end{array}$ & Ribociclib (LEE011) \\
\hline Cohorts & $\begin{array}{l}\text { - } \text { Colorectal }^{\mathrm{b}} \\
\text { - } \text { Sarcoma }^{\mathrm{b}} \\
\text { - Ovarian } \\
\text { - } \text { Cervical } \\
\text { - HNSCC } \\
\text { - Anal } \\
\text { - Gallbladder } \\
\text { - Bladder } \\
\text { - Gallbladder } \\
\text { duct } \\
\text { - GE junction } \\
\text { - Liver } \\
\text { - Skin } \\
\text { nonmelanoma } \\
\text { - Small intestine } \\
\text { - Thyroid } \\
\text { - Unknown } \\
\text { primary } \\
\text { - Vaginal } \\
\text { - Neuroendocrine }\end{array}$ & $\begin{array}{l}\text { - } \text { GIST } \\
\text { - Colorectal } \\
\text { - Ovarian } \\
\text { cystic } \\
\text { - HNSCnoid } \\
\text { - NSCLC } \\
\text { (adeno) } \\
\text { - Thymus }\end{array}$ & $\begin{array}{l}\text { - NSCLC (adeno) })^{\mathrm{b}} \\
\text { - Ovarian } \\
\text { - Uterine } \\
\text { - Appendix } \\
\text { - Small intestine } \\
\text { - Thyoma } \\
\text { - Unknown primary } \\
\text { - Breast } \\
\text { - Bladder } \\
\text { - GE junction } \\
\text { - Neuroendocrine }\end{array}$ & - Thyroid & $\begin{array}{l}\text { - } \text { Breast } \\
\text { - } \text { Colorectal } \\
\text { - } \text { HNSCC } \\
\text { - NSCLC } \\
\text { (adeno) } \\
\text { - Ovarian }\end{array}$ & $\begin{array}{l}\text { - Colorectal } \\
\text { - NSCLC } \\
\text { (adeno) } \\
\text { - Sarcoma }\end{array}$ & $\begin{array}{l}\text { - } \text { NSCLC (adeno) } \\
\text { - HNSCC } \\
\text { - Sarcoma } \\
\text { - Uterine } \\
\text { - NSCLC } \\
\text { (squamous) } \\
\text { - Breast (triple } \\
\text { negative) } \\
\text { - Mesothelioma } \\
\text { - Pancreatic } \\
\text { - } \text { Bladder } \\
\text { - } \text { Unk junction } \\
\text { - Head and neck } \\
\text { (nonsquamous) }\end{array}$ \\
\hline
\end{tabular}

Abbreviations: CR, complete response; PR, partial response; SD, stable disease. adeno, adenocarcinoma; GE, gastroesophageal; GIST, gastrointestinal stromal tumor; HNSCC, head and neck squamous cell carcinoma; NSCLC, non-small cell lung cancer.

${ }^{a}$ No cohorts (defined as $\geq 4$ patients treated) were formed for sonidegib (LDE225).

${ }^{\mathrm{b}}$ Cohort was closed for futility.

treat advanced cancers $[9,10]$. As was observed in our study, alterations in $R A S, P I K 3 C A, C D K N 2 A$, and PTEN were the most commonly observed across a range of solid tumor types included in the ProfilER study. Similarly, only a minority of patients with actionable genomic alterations received matched targeted therapies in both studies
(MOSCATO-01: $\mathrm{n}=199$ of $\mathrm{N}=411$; ProfilER: $\mathrm{n}=101$ of $\mathrm{N}=644$ ), and modest clinical benefits were observed, with objective responses in $11 \%$ and $15 \%$ of evaluable patients, respectively. It is likely that expanding access to targeted anticancer agents could increase the proportion of patients who could benefit from basket protocols. 


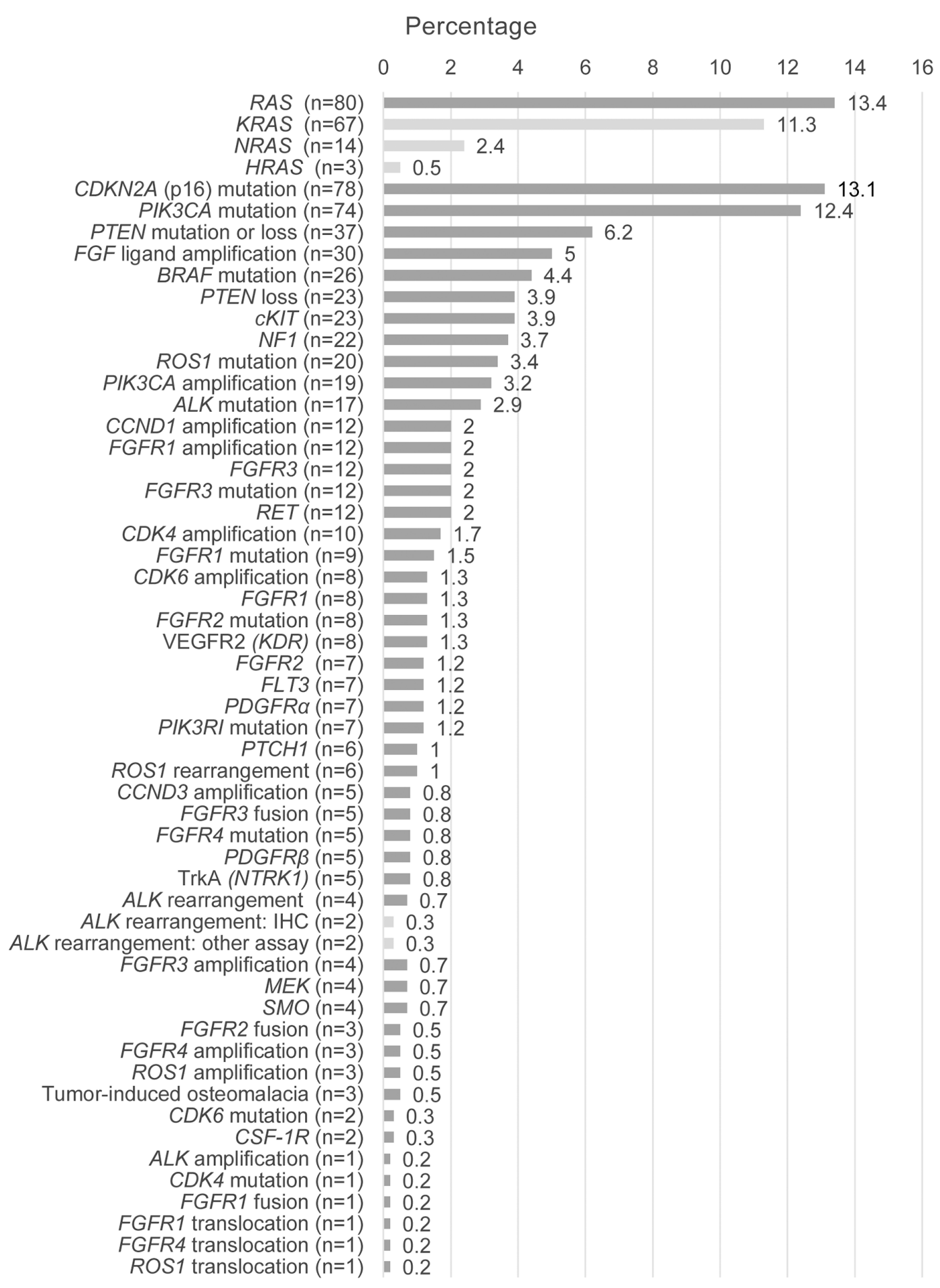

Figure 2: Summary of local alteration types $(\mathbf{N}=\mathbf{5 9 5})$. ALK, anaplastic lymphoma kinase; CCND, cyclin D; CDK, cyclindependent kinase; CDKN2A, cyclin-dependent kinase inhibitor 2A; CSF-1R, colony-stimulating factor 1 receptor; FGF, fibroblast growth factor; FGFR, fibroblast growth factor receptor; FLT3, fms-related tyrosine kinase 3; HRAS, Harvey rat sarcoma viral oncogene homolog; IHC, immunohistochemistry; KDR, kinase insert domain receptor; KRAS, Kirsten rat sarcoma viral oncogene homolog; MEK, mitogenactivated protein kinase/extracellular signal-regulated kinase kinase; NF1, neurofibromatosis type 1; NRAS, neuroblastoma RAS viral oncogene homolog; NTRK1, neurotrophic tyrosine kinase receptor type 1; PDGFR, platelet-derived growth factor receptor; PIK3CA, phosphatidylinositol 4,5-bisphosphate 3-kinase catalytic subunit $\alpha$; PIK3RI, phosphatidylinositol 3-kinase regulatory subunit polypeptide 1; PTCH1, patched 1; PTEN, phosphatase and tensin homolog; SMO, smoothened; TrkA, tropomyosin receptor kinase A; VEGFR,

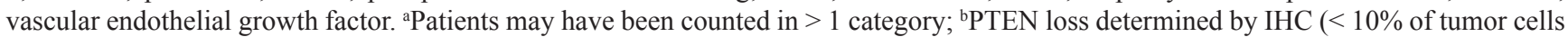
expressing PTEN at $1+$ level); ${ }^{c}$ Referring to ALK positivity. 
Table 5: Summary of clinical benefit rate (SD/PR/CR, 16 weeks)

\begin{tabular}{|c|c|c|c|c|c|c|c|c|c|}
\hline & $\begin{array}{l}\text { Buparlisib } \\
\text { (BKM120) }\end{array}$ & $\begin{array}{l}\text { Dovitinib } \\
\text { (TKI258) }\end{array}$ & $\begin{array}{c}\text { Binimetinib } \\
\text { (MEK162) }\end{array}$ & $\begin{array}{c}\text { Encorafenib } \\
\text { (LGX818) }\end{array}$ & $\begin{array}{l}\text { Sonidegib } \\
\text { (LDE225) }\end{array}$ & BGJ398 & $\begin{array}{c}\text { Ceritinib } \\
\text { (LDK378) }\end{array}$ & $\begin{array}{l}\text { Ribociclib } \\
\text { (LEE011) }\end{array}$ & Total \\
\hline Dosed patients, $n$ & 146 & 80 & 110 & 12 & 10 & $82^{\mathrm{a}}$ & 47 & 106 & $593^{\mathrm{a}}$ \\
\hline $\begin{array}{l}\text { Clinical benefit, } \\
\mathrm{n}(\%)\end{array}$ & $22(15.1)$ & $11(13.8)$ & $25(22.7)$ & $3(25.0)$ & 0 & $\begin{array}{c}12 \\
(14.6)\end{array}$ & $9(19.1)$ & $19(17.9)$ & $\begin{array}{c}101 \\
(17.0)\end{array}$ \\
\hline
\end{tabular}

Abbreviations: CR, complete response; PR, partial response; SD, stable disease.

${ }^{a}$ Excluded treatment-induced osteomalacia-only patients.

The Signature Program offered several advantages over a traditional study design. The program provided an opportunity to share emerging efficacy and safety data more quickly while minimizing the logistic challenges typical of standard clinical trials. Moreover, the patient-centric design of the program provided faster access to treatment, allowed patients to remain close to home at their current point of care, and permitted community research physicians to continue providing care rather than referring patients to a distant clinical trial center. Also, patients were preidentified based on local molecular profiling rather than undergoing central molecular prescreening. Furthermore, the adaptive statistical design required fewer enrolled patients to assess a signal, as data were analyzed for futility or efficacy more frequently rather than at the end of the study.

Another important element of this approach is that it eliminated nonenrolling sites - one of the operational inefficiencies common to site-centered cancer clinical trials. Currently, it is estimated that $20 \%$ to $30 \%$ of study sites across clinical trials enroll no patients [11]. Similarly, among Novartis-sponsored studies in the United States over the past 2 years, nearly one-third of opened sites failed to enroll any patients (data on file). With the cost of opening a study site estimated to be $\approx \$ 50,000$, regardless of whether any patients are enrolled [12], nonenrolling sites are a substantial burden on trial budgets and timelines. By limiting study participation to sites that had a potentially eligible patient ready to enroll, the Signature Program offered a more efficient and patient-centric approach that minimized this burden.

An operational challenge was to ensure a rapid and robust site-qualification process that would protect the quality of the research and data while enabling rapid site start-up. However, the program design overcame this challenge and led to a diversity of sites including academic institutions, community sites, and research networks across all states, which resulted in accelerated accrual timelines. For example, 13 cohorts reached the target accrual to allow for futility analysis in an average of 9.1 months. Four of these cohorts closed due to futility (Table 4), whereas the remaining cohorts stayed open until those studies were no longer open for enrollment.
Given that some gene alterations occur across different tumor types, the basket trial approach is driven by the interest in rapidly focusing an early drug candidate to the area(s) of greatest benefit, regardless of the overlying tumor. This approach is being used in several ongoing trials sponsored in both academia and industry. Although different in design to the Signature Program, implementation of a tissue-agnostic, molecularly driven approach led to the recent approval of pembrolizumab for the treatment of patients with any solid tumor exhibiting a specific biomarker (microsatellite instability-high or mismatch repair deficient). This is the first time that approval of a cancer treatment was based on the presence of a biomarker instead of the tumor's primary location [13]. Another example is the recently published study exploring vemurafenib in nonmelanoma cancers that specifically contain $B R A F$ V600 mutations [14]. Within the 9 arms in the study, most of the 122 patients had NSCLC, colorectal cancer, or Erdheim-Chester disease and Langerhans cell histiocytosis. In both NSCLC and Erdheim-Chester disease, the authors identified potential signals for further investigation with objective complete and partial response rates of $42 \%$ and $43 \%$, respectively. Even more recently, early results from the MyPathway study, evaluating the efficacy of 4 targeted treatments in 35 different tumor types with activating molecular alterations in the human epidermal growth factor receptor 2 (HER2), BRAF, epidermal growth factor receptor (EGFR), or Hedgehog pathways, were reported [15]. Of the 230 treated patients evaluated for a response (or discontinuing treatment prior to evaluation), 23\% had an objective response (complete or partial response). All 4 treatments produced meaningful responses, with particularly notable objective response rates in patients with human EGFR-2-amplified/overexpressing colorectal tumors (38\%) and BRAF V600-mutated NSCLC (43\%).

Collaborative genomically driven basket studies include the ongoing ASCO Targeted Agent and Profiling Utilization Registry (TAPUR) study and the NCI-MATCH trial $[16,17]$. The TAPUR study, which opened in March 2016, involves several pharmaceutical companies and consequently includes more arms than the Signature Program. Based on initial data, expansion of 4 cohorts 
Table 6: Summary of observed responses $(C R+P R)^{a}$

\begin{tabular}{|c|c|c|c|c|c|c|c|}
\hline Agent & Tumor type & Mutation & $\begin{array}{c}\text { Prior lines of } \\
\text { therapy, } \mathbf{n}\end{array}$ & $\begin{array}{c}\text { Best } \\
\text { response }\end{array}$ & $\begin{array}{c}\text { Treatment } \\
\text { duration, weeks }\end{array}$ & $\begin{array}{c}\text { Response confirmed } \\
\text { (Yes/No) }^{\mathrm{b}}\end{array}$ & $\begin{array}{l}\text { Age, } \\
\text { years }\end{array}$ \\
\hline BGJ398 & Ovarian & $\begin{array}{l}\text { FGF23 and FGF6 ligand } \\
\text { amplifications }\end{array}$ & 8 & $\mathrm{PR}^{\mathrm{c}}$ & 9.9 & No & 63 \\
\hline BGJ398 & HNSCC & $\begin{array}{l}\text { FGF19, FGF4, FGF23, FGF3, and } \\
\text { FGF6 ligand amplifications }\end{array}$ & 3 & PR & 63 & Yes & 49 \\
\hline BGJ398 & HNSCC & $\begin{array}{l}\text { FGFR3 mutation; FGF3, FGF4, } \\
\text { and FGF19 ligand amplifications }\end{array}$ & Unknown & PR & 16 & Yes & 59 \\
\hline BGJ398 & $\begin{array}{l}\text { Tumor-induced } \\
\text { osteomalacia }^{\mathrm{d}}\end{array}$ & $F G F R 1$ translocation & $0^{\mathrm{e}}$ & PR & 77.9 & Yes & 62 \\
\hline BGJ398 & HNSCC & $\begin{array}{l}\text { FGF3, FGF4, and FGF19 ligand } \\
\text { amplifications }\end{array}$ & 4 & PR & 21.6 & No & 71 \\
\hline BGJ398 & $\mathrm{CNS}$ & $\begin{array}{l}\text { FGFR3 amplification; FGFR3 } \\
\text { fusion }\end{array}$ & 1 & PR & 71.9 & Yes & 45 \\
\hline BGJ398 & Ovarian & $F G F R 1$ amplification & 4 & $\mathrm{PR}^{\mathrm{c}}$ & 6.3 & No & 73 \\
\hline BGJ398 & $\begin{array}{c}\text { NSCLC } \\
\text { (squamous) }\end{array}$ & FGFR1 mutation & 4 & PR & 30.4 & Yes & 72 \\
\hline BGJ398 & Bladder & FGFR3 mutation & 3 & $\mathrm{PR}^{\mathrm{c}}$ & 12.9 & No & 80 \\
\hline BGJ398 & HNSCC & $\begin{array}{l}\text { FGF3, FGF4, and FGF19 ligand } \\
\text { amplifications }\end{array}$ & 1 & $\mathrm{PR}^{\mathrm{c}}$ & 15 & No & 56 \\
\hline BGJ398 & $\begin{array}{l}\text { NSCLC } \\
\text { (squamous) }\end{array}$ & $F G F R 2$ mutation & 2 & PR & $96.6^{\mathrm{f}}$ & Yes & 74 \\
\hline LDK378 & $\begin{array}{l}\text { Lung, non- } \\
\text { small cell } \\
\text { adenocarcinoma }\end{array}$ & ROS1 rearrangement & 4 & PR & 29.3 & Yes & 81 \\
\hline LDK378 & Lymphoma & $A L K$ mutation & 3 & $\mathrm{PR}$ & $102.7^{\mathrm{f}}$ & Yes & 22 \\
\hline LDK378 & $\begin{array}{c}\text { Lung, non- } \\
\text { small cell } \\
\text { adenocarcinoma }\end{array}$ & ROS1 rearrangement & 3 & PR & 23.9 & Yes & 58 \\
\hline BKM120 & Cervical & PTEN loss (by IHC) & 4 & PR & 24 & No & 57 \\
\hline BKM120 & Vaginal & PIK3CA & 1 & $\mathrm{CR}$ & 7.6 & Yes & 68 \\
\hline BKM120 & HNSCC & $\begin{array}{l}P I K 3 C A \text { and } P I K 3 C A \\
\text { amplification }\end{array}$ & 1 & PR & 32.3 & Yes & 65 \\
\hline TKI258 & Ovarian & FGFR2 & 5 & PR & 32.7 & No & 74 \\
\hline TKI258 & GIST & cKit & 3 & PR & 33.1 & Yes & 49 \\
\hline MEK162 & AML & $N R A S$ & 1 & $\mathrm{CR}$ & 20 & NA & 68 \\
\hline MEK162 & Ovarian & $\begin{array}{l}\text { KRAS (KRAS amplification and } \\
\quad \text { KRAS G12D mutation) }\end{array}$ & 5 & PR & 44.3 & Yes & 78 \\
\hline MEK162 & Ovarian & $K R A S$ & 3 & PR & 15.9 & No & 45 \\
\hline MEK162 & Thyroid & $N R A S$ & 1 & PR & 36 & Yes & 75 \\
\hline MEK162 & Uterine & $K R A S(G 12 V)$ & 7 & PR & 21.6 & Yes & 59 \\
\hline MEK162 & Myeloma & $K R A S$ & 2 & $\begin{array}{l}\text { Very good } \\
\text { PR }\end{array}$ & 16.6 & NA & 59 \\
\hline LEE011 & Bladder & $C C N D 1$ amplification & 2 & PR & 43 & Yes & 53 \\
\hline LEE011 & Ovarian & CDK6 mutation & 2 & PR & 38.1 & No & 66 \\
\hline LEE011 & Sarcoma & $C D K 4$ amplification & 1 & PR & 53.7 & Yes & 25 \\
\hline LEE011 & $\begin{array}{l}\text { Unknown } \\
\text { primary }\end{array}$ & CDK6 amplification & 1 & PR & $153.1^{\mathrm{f}}$ & Yes & 59 \\
\hline
\end{tabular}

Abbreviations: ALK, anaplastic lymphoma kinase; AML, acute myeloid leukemia; CCND, cyclin D; CDK, cyclic-dependent kinase; CNS, central nervous system; CR, complete response; FGF, fibroblast growth factor; FGFR, fibroblast growth factor receptor; GIST, gastrointestinal stromal tumor; HNSCC, head and neck squamous cell cancer; IHC, immunohistochemistry; KRAS, Kirsten rat sarcoma viral oncogene homolog; NA, not applicable; NRAS, neuroblastoma RAS viral oncogene homolog; NSCLC, non-small cell lung cancer; PIK3CA, phosphatidylinositol 4,5-bisphosphate 3-kinase catalytic subunit $\alpha$; PR, partial response; PTEN, phosphate and tensin homolog.

${ }^{a}$ All patients experiencing a CR or PR at any time are included. Note that not all responses were confirmed responses by Response Evaluation Criteria In Solid Tumors or other related criteria.

${ }^{b}$ Unconfirmed response; patients may not have had a confirmatory scan due to protocol deviation or withdrawal from the trial before the confirmatory scan.

'Response not $>16$ weeks.

${ }^{\mathrm{d}}$ As defined by protocol.

ePatient had not been treated with prior chemotherapy/medication, but had 1 prior radiotherapy and surgery.

fPatient was still on study at time of data cutoff. 
and closure of a further cohort was recommended. The NCI-MATCH trial, which will enroll up to 6000 patients, opened in August 2015 with 10 arms and showed remarkably fast accrual of patients for molecular profiling, thereby demonstrating the interest in precision oncology among patients and physicians. However, the study suspended recruitment due to challenges in matching sufficient numbers of profiled patients to targeted therapies. The study reopened with 24 treatment arms.

The Signature Program contrasts with the NCIMATCH study in several ways. First, NCI-MATCH requires a fresh biopsy with molecular characterization, whereas Signature allowed enrollment based on local testing of archival or fresh tissue, and only allowed patients to enroll after it was confirmed their tumor alteration was relevant to a specific protocol. Although obtaining a proximal tumor sample is theoretically appealing, because it minimizes the impact of genomic evolution, it has the clear disadvantage that most patients who wait for tissue characterization may not "match" to a treatment arm. Further, the statistical designs used in the 2 studies differed, with the Signature Program using a modified Bayesian adaptive design with a hierarchical model, allowing for dynamic borrowing of information, across tumor types within each of its basket trials. Critically, while the NCI-MATCH study does not use a Bayesian design, the Signature Program uses an improvement of the Bayesian hierarchical model. The method clusters tumor types such that those within the same cluster contribute more strongly to each other than do those outside the cluster. Clusters may be defined in advance, but an adaptive design also allows for clusters to be established based on similar outcomes, thereby increasing the odds of clinical benefit and enabling more signal finding $[6,18]$.

The Bayesian approach has been increasingly employed in all phases of drug development [18-23], and the specific advantages of the Bayesian design used in the Signature trials have been previously described in detail $[6,24]$. In brief, Berry [6] compared the performance of the adaptive Bayesian hierarchical approach used in the Signature Program with that of the standard inferential and design approach used in the NCI-MATCH and vemurafenib trials, and determined that adaptive and hierarchical borrowing contribute to the accuracy and efficiency (smaller sample size) of indication finding in the Signature Program. Thus, using basket trials in the manner described has the potential for added efficiency in drug development. While the differential responses in patients may be due to tumor heterogeneity, rapid tumor adaptation to target inhibition, or other tissue-specific mechanisms, the strength of the signal (or lack thereof) in small tissue-specific cohorts interrogated through adaptive designs provides important clues to guide investigators toward clinical settings in which treatment relevance is most easily determined. Given the substantial cost of downstream development, which can be as high as $\$ 2.8$ billion [25], the ability to rapidly focus resources on the most promising clinical setting(s) can be expected to not only speed development, but also reduce overall costs. Whether this promise can be realized will depend on effective implementation of this type of signal-generation approach.

Several limitations of our approach should be considered. The most important limitation is that singleagent treatment with targeted agents has often produced either limited efficacy or limited duration of response. This limitation may be overcome by using combination therapy with a second compound either directed at another part of the pathway or with a different mechanism of action, such as an agent that is synergistic, additive, or concurrent chemotherapy. Similar trial designs could be used to interrogate the value of various combination approaches across multiple tumor types. A second potential limitation is the rarity of some mutations across the spectrum of most tumors. Mutation rates within tumor types remain an important covariate for patient accrual, with mutations of interest often occurring in a small fraction of any specific tumor type. Although the Signature platform expanded the ability to capture patients with mutations of interest from diverse sites (eg, academic institutions and community sites) and from across the country, a very low mutation rate in a very limited number of tumor types remained a limiting factor, as seen in the sonidegib protocol, in which only 10 patients were accrued over 11 months. A third concern is that weaker, but potentially useful, signals could be missed in the context of small cohorts and heterogeneous populations. However, having a threshold for signal detection results in focusing limited resources on areas that are likely to be of greatest overall clinical benefit. Lastly, given the noncomparative nature of these single-arm protocols, it is not possible to describe the true clinical efficacy, or lack thereof, and thus interpretation of clinical responses should be made with caution. Tissuespecific studies with appropriate comparator arms would be required if early signals of clinical benefit are detected.

The Signature Program was a successful approach. It led to rapid signal finding, reduced patient exposure to toxicity, substantially shortened trial start-up times compared with conventional approaches, and cost-savings as a result of not opening multiple unnecessary trials and avoiding the cost-burden of nonenrolling and nonaccruing sites. The success of the Signature Program has led to conventional pivotal and exploratory studies in single indications incorporating several of the program features, including rapid start-up of nonpreselected sites. Each site was created when a patient with an actionable alteration was recommended for participation in the study. This concept highlights one of the most important advances in clinical trial methodology, that is, the broadening of the application of randomization outside typical venues for clinical trials [26]. Our evolving knowledge 
of cancer biology underscores the need for a paradigm shift in the traditional clinical trial approach [6]. The Signature Program highlights one way that the clinical trial is changing and serves as a sign of the eventual merger between clinical research and clinical practice. Subsequent Signature studies using combination therapies, predicted to be successful based on additional preclinical data, will address some of the program limitations and help determine the role of such an approach in drug development.

\section{MATERIALS AND METHODS}

\section{Study design}

Each protocol evaluated the efficacy and safety of 1 agent (buparlisib, dovitinib, binimetinib, encorafenib, sonidegib, BGJ398, ceritinib, or ribociclib) in patients with any solid tumor or hematologic malignancy that had an actionable genetic alteration, as assessed by a local Clinical Laboratory Improvement Amendments-certified laboratory, and disease that had progressed on or after standard treatment. All protocols had a similar study design (Figure 1).

Once an actionable genetic alteration was identified, the research physician contacted Novartis and a startup package for the relevant protocol (including a fixed contract, central institutional review board [IRB]approved protocol, standard budget, and set of standard informed consent forms) was sent. Institutions residing in the United States and having conducted industry research in the last year were considered to be researchqualified sites and were eligible for participation. The selection of an actionable alteration was left to the discretion of the investigator; however, Novartis was available for consultation if needed. Patients with $>1$ actionable mutation were enrolled in a trial for the relevant mutation(s) at the investigator's discretion. A cohort for a particular tumor type was formed after $\geq 4$ patients with that tumor type were enrolled.

A tumor tissue sample (archival or fresh) was submitted to Novartis upon patient enrollment for post hoc central profiling in a panel of $>288$ cancer-related genes, which was followed by a confirmatory test against a larger panel of genes.

Patients initiated treatment once eligibility criteria were confirmed by Novartis. Enrollment requirements were sponsor approval, a prescreening phone call, and completion of proper regulatory forms. Local IRBs were not used, and certain local IRBs required a waiver-ofjurisdiction form. Following an expedited site initiation visit, the protocol was opened for the preidentified patient and for future accrual at the site. Patients received treatment until disease progression, unacceptable toxicity, death, or discontinuation from study treatment.

\section{Eligibility criteria}

Eligible patients must have had received $\geq 1$ prior treatment and have had no remaining standard treatment options. Tumor types for which the agent has shown no benefit and those for which key studies are planned or ongoing were excluded.

\section{Endpoints and assessments}

The primary endpoint of each study was the clinical benefit rate (defined as complete response, partial response, or stable disease) at 16 weeks per investigator assessment, Response Evaluation Criteria In Solid Tumors v1.1, or appropriate hematologic criteria. Secondary endpoints included response rate, duration of response, progression-free survival, and overall survival. Exploratory endpoints included correlations between local and central molecular profiling data to evaluate the mutational pathway status of complementary DNA and the relationship to the response to treatment. Preliminary safety and tolerability results were also collected.

\section{Statistical analysis}

To produce a higher statistical power (and lower risk of type I error) with fewer patients, we evaluated outcomes using a patient-sparing, Bayesian hierarchical model with clustering and dynamic borrowing $[6,27]$. Cohorts with similar historical response rates were clustered using a Dirichlet process mixture model. Historical response rates were determined by examining published overall response rate data for patients who had received several lines of standard-of-care therapy. Hierarchical models were then placed over the cohorts within each cluster to determine the appropriate extent of borrowing between cohorts. Because the model does not allow borrowing across clusters, borrowing across dissimilar subgroups was minimized by assigning cohorts with dissimilar responses to different clusters.

Interim analyses were conducted to evaluate early futility and success in cohorts with a minimum of 10 patients at 16 weeks. A lack of clinical improvement in $\geq 10$ patients within a cohort established futility. Clinical futility was defined as $<10 \%$ probability that the response rate in a group exceeded the historical rate. Clinical success observed in a cohort of 15 to 30 patients, depending on the strength of the response signal within the cohort and in the other cohorts for that compound, confirmed a positive signal. If there was $\geq 95 \%$ probability that the response rate in a group exceeded the historical rate, observed in $\geq 15$ patients within a cohort, enrollment was stopped early for success. 


\section{Ethical oversight}

This clinical study was designed, implemented, and reported in accordance with the International Conference on Harmonisation-Harmonised Tripartite Guidelines for Good Clinical Practice, with applicable local regulations, and the Declaration of Helsinki. The study protocol and proposed informed consent form were reviewed and approved by a central IRB (Quorum) before study start. All patients provided informed consent.

\section{Abbreviations}

5-FU, 5-fluorouracil; Adeno, adenocarcinoma; ALK, anaplastic lymphoma kinase; ALL, acute lymphocytic leukemia; AML, acute myeloid leukemia; CCND, cyclin D; CDK, cyclin-dependent kinase; CDKN2A, cyclin-dependent kinase inhibitor 2A; CLIA, Clinical Laboratory Improvement Amendments; CML, chronic myeloid leukemia; CNS, central nervous system; $\mathrm{CR}$, complete response; CSF-1R, colony-stimulating factor 1 receptor; ECOG, Eastern Cooperative Oncology Group; ER, estrogen receptor; FGF, fibroblast growth factor; FGFR, fibroblast growth factor receptor; FLT3, fms-related tyrosine kinase 3; FOLFOX, leucovorin, 5-fluorouracil, oxaliplatin; GE, gastroesophageal; GIST, gastrointestinal stromal tumor; HNSCC, head and neck squamous cell carcinoma; HRAS, Harvey rat sarcoma viral oncogene homolog; IHC, immunohistochemistry; IRB, institutional review board; KDR, kinase insert domain receptor; KRAS, Kirsten rat sarcoma viral oncogene homolog; MEK, mitogen-activated protein kinase/extracellular signal-regulated kinase kinase; NF1, neurofibromatosis type 1; NRAS, neuroblastoma RAS viral oncogene homolog; NSCLC, non-small cell lung cancer; NTRK1, neurotrophic tyrosine kinase receptor type 1; PDGFR, platelet-derived growth factor receptor; PI3K, phosphatidylinositol 3-kinase; PIK3CA, phosphatidylinositol 4,5-bisphosphate 3-kinase catalytic subunit $\alpha$; PIK3R1, phosphatidylinositol 3-kinase regulatory subunit polypeptide 1; PR, partial response; PS, performance status; PTCH1, patched 1; PTEN, phosphatase and tensin homolog; RTK, receptor tyrosine kinase; SIV, site initiation visit; SMO, smoothened; TrkA, tropomyosin receptor kinase A; VEGFR, vascular endothelial growth factor receptor.

\section{Author contributions}

J.P., M.T., T.M.B., F.B., A. Spira, F.M-B., and S.A.P-P. enrolled patients, performed research, and contributed to data collection and interpretation; D.A.B contributed to the study's statistical design and data interpretation; E.D.S, B.P.K, S.S., and A. Salvado contributed to the study design and data interpretation. All authors were involved with drafting the manuscript and approved the final version.

\section{ACKNOWLEDGMENTS}

We thank the patients, study investigators, site staff, Sudha Parasuraman, Stephanie Petrone, Tina Grasso, Rajinder Sidhu, Erica Stealey, Alok Shrestha, Linda Karpiak, Flora Miranda, Renata Matys, Susan Snodgrass, Theresa White, Claudia Lebedinsky, Joy Ero, Neeraj Pandey, and Ghulam Warsi. Eric D. Slosberg is currently an employee of Daiichi Sankyo, Inc, Basking Ridge, NJ, USA, but was with Novartis at the time of manuscript development. Financial support for medical editorial assistance was provided by Novartis Pharmaceuticals Corporation. We thank Karen Chinchilla, $\mathrm{PhD}$, from ArticulateScience, LLC, for assistance with this manuscript.

\section{CONFLICTS OF INTEREST}

Dr Slosberg was an employee of and stockholder in Novartis at the time the study was conducted and holds intellectual property assigned to Novartis. Dr Kang is an employee of and stockholder in Novartis. Dr Taylor has received honoraria from Eisai and has consulted for or held an advisory role with Eisai and Onyx. Dr Berry is employed by, has a leadership role in, and has ownership in Berry Consultants. Dr Braiteh has received honoraria from Amgen, BIND Therapeutics, Boehringer Ingelheim, Caris Life Sciences, Dendreon, Foundation Medicine, Incyte, Insys, Molecular Health, Novartis, Pfizer, Saladax Pharmaceuticals, and Sanofi; has participated in speakers bureaus for Amgen, Bayer, Boehringer Ingelheim, Bristol-Myers Squibb, Caris Life Sciences, Celgene, Genomic Health, Incyte, Insys, Myriad, Novartis, Pfizer, and Sanofi; has received travel reimbursement from Amgen, AstraZeneca/MedImmune, Bayer, Bristol-Myers Squibb, Caris Life Sciences, Celgene, Eli Lilly, Foundation Medicine, Genomic Health, Gilead, Heron Therapeutics, Incyte, Insys, Molecular Health, Pfizer, Roche/Genentech, Saladax Pharmaceuticals, and Sanofi; and has received institutional research funding from AbbVie, Active Biotech, Amgen, AstraZeneca/ MedImmune, Bayer, BIND Therapeutics, BioMarin, Biotheranostics, BN Therapeutics, Boston Biomedical, Bristol-Myers Squibb, Caris Life Sciences, Celgene, Cell Therapeutics, Daiichi Sankyo, Dendreon, Eli Lilly, Endocyte, Exelixis, Foundation Medicine, Genomic Health, Gilead, GlaxoSmithKline, Halozyme Therapeutics, Heron Therapeutics, ImClone, Incyte, Insys, Janssen, MEI Pharma, Merrimack, Millennium, Molecular Health, Novartis, Pfizer, Pharmacyclics, Plexxikon, PSMA, Roche/ Genentech, Saladax Pharmaceuticals, Sanofi, Seattle Genetics, and Viamet. Dr Spira has received honoraria from Novartis, Roche, Clovis Oncology, and Ariad; has held a consulting or advisory role for Roche/Genentech, Ariad, and Clovis Oncology; has received research funding from Roche, AstraZeneca, Boehringer Ingelheim, 
Astellas Pharma, Clovis Oncology, MedImmune, Novartis, NewLink Genetics, Benovus Bio, and Incyte; has provided expert testimony for Novartis; and has received travel reimbursement from Roche, Ariad, and Clovis Oncology. Dr Meric-Bernstam has received honoraria from Genentech and Roche Diagnostics; has held a consulting or advisory role for Genentech, Novartis, Roche, Inflection Biosciences, and Celgene; and has received research funding from Novartis, AstraZeneca, Taiho Pharmaceutical, Genentech, Calithera Biosciences, Debiopharm Group, Bayer, Aileron Therapeutics, Puma Biotechnology, Verastem, and CytomX Therapeutics. Dr Stein was formerly employed by Novartis, is currently employed by Incyte, and has stock or other ownership in both companies. Dr Piha-Paul has received research funding from GlaxoSmithKline, Incyte, AbbVie, Novartis, Merck, Xuanzhu, Curis, Principia Biopharma, Samumed, Puma Biotechnology, Helix, BioMarin, and Cerulean Pharma. Dr Salvado was an employee of and stockholder in Novartis at the time the study was conducted. Drs Peguero and Bauer have nothing to disclose.

\section{FUNDING}

Provided by Novartis Pharmaceuticals Corporation.

\section{PREVIOUS PRESENTATIONS OF STUDY RESULTS}

Initial clinical data were presented at the American Society of Clinical Oncology Annual Meetings in 2014 and 2015 and at the American Society of Hematology Annual Meeting in 2014.

\section{REFERENCES}

1. Lopez-Chavez A, Thomas A, Rajan A, Raffeld M, Morrow B, Kelly R, Carter CA, Guha U, Killian K, Lau CC, Abdullaev Z, Xi L, Pack S, et al. Molecular profiling and targeted therapy for advanced thoracic malignancies: a biomarker-derived, multiarm, multihistology phase II basket trial. J Clin Oncol. 2015; 33:1000-1007.

2. Ellis MJ, Perou CM. The genomic landscape of breast cancer as a therapeutic roadmap. Cancer Discov. 2013; $3: 27-34$

3. Mandrekar SJ, Dahlberg SE, Simon R. Improving clinical trial efficiency: thinking outside the box. Am Soc Clin Oncol Educ Book. 2015; 35:e141-e147.

4. Redig AJ, Jänne PA. Basket trials and the evolution of clinical trial design in an era of genomic medicine. J Clin Oncol. 2015; 33:975-977.

5. Hyman DM, Blay JY, Chau I, Raje NS, Fernandez MEE, Wolf J, Sirzen F, Veronese ML, Mitchell L, Puzanov I, Baselga J. VE-BASKET, A first-in-kind, phase II, histologyindependent "basket" study of vemurafenib (VEM) in nonmelanoma solid tumors harboring BRAF V600 mutations (V600m). J Clin Oncol. 2014; 32:abstract 2533.

6. Berry DA. Emerging innovations in clinical trial design. Clin Pharmacol Ther. 2016; 99:82-91.

7. Yakirevich E, Resnick MB, Mangray S, Wheeler M, Jackson CL, Lombardo KA, Lee J, Kim KM, Gill AJ, Wang K, Gowen K, Sun J, Miller VA, et al. Oncogenic ALK fusion in rare and aggressive subtype of colorectal adenocarcinoma as a potential therapeutic target. Clin Cancer Res. 2016; 22:3831-3840.

8. Lamberti MJ, Brothers C, Manak D, Getz K. Benchmarking the study initiation process. Ther Innov Regul Sci. 2013; 47:101-109.

9. Massard C, Michiels S, Ferte C, Le Deley MC, Lacroix L, Hollebecque A, Verlingue L, Ileana E, Rosellini S, Ammari S, Ngo-Camus M, Bahleda R, Gazzah A, et al. Highthroughput genomics and clinical outcome in hard-to-treat advanced cancers: results of the MOSCATO 01 trial. Cancer Discov. 2017; 7:586-95.

10. Tredan O, Corset V, Wang Q, Varnier R, Pacaud C, Torroja A, Luppi N, Ezzalfani M, Myard M, Jiang X, Attignon V, Pissaloux D, Baudet C, et al. Routine molecular screening of advanced refractory cancer patients: an analysis of the first 2490 patients of the ProfiLER study. J Clin Oncol. 2017; 35:abstract LBA100.

11. Lynam EB, Leaw J, Wiener MB. A patient focused solution for enrolling clinical trials in rare and selective cancer indications: a landscape of haystacks and needles. Drug Inf J. 2012; 46:472-478.

12. Handelsman D. Optimizing clinical research operations with business analytics. Paper presented at: SAS Global Forum 2011; April 4-7, 2011; Las Vegas NV. Paper 204-2011:1-6.

13. FDA. FDA approves first cancer treatment for any solid tumor with a specific genetic feature [press release]. Silver Spring, MD: US Food and Drug Administration; May 23, 2017. https:// www.fda.gov/newsevents/newsroom/pressannouncements/ ucm560167.htm. Accessed January 25, 2018.

14. Hyman DM, Puzanov I, Subbiah V, Faris JE, Chau I, Blay JY, Wolf J, Raje NS, Diamond EL, Hollebecque A, Gervais $\mathrm{R}$, Elez-Fernandez ME, Italiano A, et al. Vemurafenib in multiple nonmelanoma cancers with BRAF V600 mutations. N Engl J Med. 2015; 373:726-736.

15. Hainsworth JD, Meric-Bernstam F, Swanton C, Hurwitz H, Spigel DR, Sweeney C, Burris H, Bose R, Yoo B, Stein A, Beattie M, Kurzrock R. Targeted therapy for advanced solid tumors on the basis of molecular profiles: results from MyPathway (cap M and P), an open-label, phase IIa multiple basket study. J Clin Oncol. 2018; 36:536-542.

16. The American Society of Clinical Oncology. ASCO expands TAPUR study enrollment after promising initial treatment outcomes seen [news release]. Alexandria, VA: American Society of Clinical Oncology; November 16, 2017. https://www.asco.org/about-asco/press-center/ 
news-releases/asco-expands-tapur-study-enrollment-afterpromising-initial. Accessed January 25, 2018.

17. National Cancer Institute. NCI-MATCH Trial (Molecular Analysis for Therapy Choice). http://www.cancer.gov/ about-cancer/treatment/clinical-trials/nci-supported/ncimatch. Accessed June 20, 2017.

18. Kang B, Slosberg E, Snodgrass S, Lebedinsky C, Berry DA, Corless CL, Stein S, Salvado A. The Signature Program: bringing the protocol to the patient. Clin Pharmacol Ther. 2015; 98:124-126.

19. Berry DA. The brave new world of clinical cancer research: adaptive biomarker-driven trials integrating clinical practice with clinical research. Mol Oncol. 2015; 9:951-959.

20. Woodcock J, LaVange LM. Master protocols to study multiple therapies, multiple diseases, or both. N Engl J Med. 2017; 377:62-70.

21. Das S, Lo AW. Re-inventing drug development: a case study of the I-SPY 2 breast cancer clinical trials program. Contemp Clin Trials. 2017; 62:168-174.

22. Park JW, Liu MC, Yee D, Yau C, van't Veer LJ, Symmans WF, Paoloni M, Perlmutter J, Hylton NM, Hogarth M, DeMichele A, Buxton MB, Chien AJ, et al, and I-SPY 2 Investigators. Adaptive randomization of neratinib in early breast cancer. N Engl J Med. 2016; 375:11-22.

23. Rugo HS, Olopade OI, DeMichele A, Yau C, van't Veer LJ, Buxton MB, Hogarth M, Hylton NM, Paoloni M, Perlmutter J, Symmans WF, Yee D, Chien AJ, et al, and I-SPY 2 Investigators. Adaptive randomization of veliparib-carboplatin treatment in breast cancer. N Engl J Med. 2016; 375:23-34.

24. Berry DA. Bayesian clinical trials. Nat Rev Drug Discov. 2006; 5:27-36.

25. DiMasi JA, Grabowski HG, Hansen RW. Innovation in the pharmaceutical industry: new estimates of R\&D costs. J Health Econ. 2016; 47:20-33.

26. Sherman RE, Anderson SA, Dal Pan GJ, Gray GW, Gross T, Hunter NL, LaVange L, Marinac-Dabic D, Marks PW, Robb MA, Shuren J, Temple R, Woodcock J, et al. Real-world evidence - what is it and what can it tell us? N Engl J Med. 2016; 375:2293-2297.

27. Berry SM, Broglio KR, Groshen S, Berry DA. Bayesian hierarchical modeling of patient subpopulations: efficient designs of phase II oncology clinical trials. Clin Trials. 2013; 10:720-734.

28. Burger MT, Pecchi S, Wagman A, Ni ZJ, Knapp M, Hendrickson T, Atallah G, Pfister K, Zhang Y, Bartulis S, Frazier K, Ng S, Smith A, et al. Identification of NVPBKM120 as a potent, selective, orally bioavailable class I PI3 kinase inhibitor for treating cancer. ACS Med Chem Lett. 2011; 2:774-779.
29. Lee SH, Lopes de Menezes D, Vora J, Harris A, Ye H, Nordahl L, Garrett E, Samara E, Aukerman SL, Gelb AB, Heise C. In vivo target modulation and biological activity of CHIR-258, a multitargeted growth factor receptor kinase inhibitor, in colon cancer models. Clin Cancer Res. 2005; 11:3633-3641.

30. Ascierto PA, Schadendorf D, Berking C, Agarwala SS, van Herpen CM, Queirolo P, Blank CU, Hauschild A, Beck JT, St-Pierre A, Niazi F, Wandel S, Peters M, et al. MEK162 for patients with advanced melanoma harbouring NRAS or Val600 BRAF mutations: a nonrandomised, open-label phase 2 study. Lancet Oncol. 2013; 14:249-256.

31. Stuart DD, Li N, Poon DJ, Aardalen K, Kaufman S, Merritt H, Salangsang F, Lorenzana E, Li A, Ghoddusi M, Caponigro G, Sun F, Kulkarni S, et al. Preclinical profile of LGX818: a potent and selective raf kinase inhibitor. Cancer Res. 2012; 72:abstract 3790.

32. Pan S, Wu X, Jiang J, Gao W, Wan Y, Cheng D, Han D, Liu J, Englund NP, Wang Y, Peukert S, Miller-Moslin K, Yuan J, et al. Identification of NVP-BKM120 as a potent, selective, orally bioavailable class I PI3 kinase inhibitor for treating cancer. ACS Med Chem Lett. 2010; 1:130-134.

33. Guagnano V, Kauffmann A, Wöhrle S, Stamm C, Ito M, Barys L, Pornon A, Yao Y, Li F, Zhang Y, Chen Z, Wilson CJ, Bordas V, et al. FGFR genetic alterations predict for sensitivity to NVP-BGJ398, a selective pan-FGFR inhibitor. Cancer Discov. 2012; 2:1118-1133.

34. Marsilje TH, Pei W, Chen B, Lu W, Uno T, Jin Y, Jiang T, Kim S, Li N, Warmuth M, Sarkisova Y, Sun F, Steffy A, et al. Synthesis, structure-activity relationships, and in vivo efficacy of the novel potent and selective anaplastic lymphoma kinase (ALK) inhibitor 5-chloroN2-(2-isopropoxy-5-methyl-4-(piperidin-4-yl)phenyl)N4-(2-(isopropylsulfonyl)phenyl)pyrimidine-2,4-diamine (LDK378) currently in phase 1 and phase 2 clinical trials. J Med Chem. 2013; 56: 5675-5690.

35. Rader J, Russell MR, Hart LS, Nakazawa MS, Belcastro LT, Martinez D, Li Y, Carpenter EL, Attiyeh EF, Diskin SJ, Kim S, Parasuraman S, Caponigro G, et al. Dual CDK4/ CDK6 inhibition induces cell-cycle arrest and senescence in neuroblastoma. Clin Cancer Res. 2013; 19:6173-6182.

36. Xeloda (sonidegib) [package insert]. East Hanover, NJ: Novartis Pharmaceuticals Corp; 2015.

37. Zykadia (ceritinib) [package insert]. East Hanover, NJ: Novartis Pharmaceuticals Corp; 2015.

38. Kisqali (ribociclib) [package insert]. East Hanover, NJ: Novartis Pharmaceuticals Corp; 2017. 